\title{
A History of Violence: Field Evidence on Trauma, Discounting and Present Bias
}

\author{
Alex Imas* \\ Michael A. Kuhn ${ }^{\dagger}$ \\ Carnegie Mellon University \\ University of Oregon \\ Vera Mironova ${ }^{\ddagger}$ \\ University of Maryland and Harvard University \\ May 4, 2015
}

\begin{abstract}
The extent to which individuals discount the future and whether they discount in a timeconsistent fashion is an important determinant of their life outcomes. Prior work shows a weak (Voors et al. 2012) or insignificant (Bchir and Willinger, 2013) effect of trauma on time preferences. However, these studies offered choices between rewards that all lay in the future, and hence could not identify an impact on impulsivity - the tendency to choose a smaller reward available immediately over a larger, later reward. In this paper, we partnered with a grocery store near an area of active conflict in the Democratic Republic of Congo that offered a unique opportunity to identify the effects of exposure to violence on impulsivity. In contrast to prior work, we find that direct exposure to violence had a large and significant effect on impulsivity: exposed individuals chose the smaller reward nearly twice as often when it was available immediately than unexposed individuals. We also demonstrate that providing individuals with a delay between information about the choice and the choice itself mitigates the differences in behavior between exposed and unexposed groups. Our findings suggest that enforcing a cooling off period between income notification and consumption opportunities may help generate more patient choices and mitigate elevated impulsivity. Our results have implications for policies aimed at alleviating the deleterious effects of present bias and the role of deliberation in the structure of commitment contracts.
\end{abstract}

JEL Classification: C93, D14, F51

Keywords: present bias, violence, field experiments

${ }^{*}$ Carnegie Mellon University, Social and Decision Sciences, 5000 Forbes Ave, Porter Hall 208, Pittsburgh, PA 15213 USA. E-mail: aimas@andrew.cmu.edu. Web page: sites.google.com/site/alexoimas

${ }^{\dagger}$ University of Oregon, Department of Economics, 1285 University of Oregon, Eugene, OR 97403 USA. E-mail: mkuhn@uoregon.edu. Web page: pages.uoregon.edu/mkuhn

${ }^{\ddagger}$ University of Maryland, Department of Government and Politics, 3140 Tydings Hall, College Park, MD 20742 USA. E-mail: vmironov@umd.edu. Web page: vmironova.net 


\section{Introduction}

Calculations of the economic costs of war and violence have typically focused on the loss of existing capital, disruptions to future capital development, and human casualties as a result of the immediate destruction (Stewart, 1993). However, for those who survive, exposure to violence and other trauma has been shown to affect behavior and lead to costly, suboptimal decision-making long after the negative event has passed. These second-order effects of exposure to violence are likely dwarfed by the direct effects in the immediate aftermath, but in the long run, they are part of what determines when and how recovery occurs. If violence changes people's preferences, it will also change the effects of policies implemented on behalf of those people.

Research in psychology has demonstrated that exposure to violence and other trauma (e.g. extreme poverty) has complex, deleterious long-run effects on both mental and physical health (Boscarino, 2006; Yehuda, 2006). Recent work has also shown that such experiences also affect economic decision-making. Traumatic experiences lead to significant changes in risk taking across a variety of contexts (Callen et al., 2014; Voors et al., 2012), and affect financial decision making decades into the future (Malmendier and Nagel, 2011).

In this paper, we explore the effect of violence on time discounting. Through a field experiment in the Democratic Republic of Congo, we implement a novel study designed to study a specific type of time discounting - present bias. Discounting is a fundamental aspect of preferences for understanding behavioral changes due to violence because the extent to which individuals discount the future and whether they discount in a time-consistent fashion is an important determinant of their life time outcomes (Frederick et al., 2002). Increased impatience has been shown to predict both low saving and investment (Laibson, 1997) and suboptimal purchasing decisions (Zauberman, 2003), while present bias predicts poor control of spending (Dohmen et al., 2010), high levels of credit card debt (Meier and Sprenger, 2010) and poor overall health outcomes (DellaVigna and Malmendier, 2006).

Although much of the prior literature on time preferences has typically examined tradeoffs between monetary rewards, recent work has argued and showed that identifying present bias requires tradeoffs between more direct proxies for consumption (Augenblick et al., 2013). As such, we worked with a local grocery store in Bukavu in the Democratic Republic Congo (DRC) to design 
an experiment to measure time preferences over consumption goods. The grocery store was located in a region with a population heterogenous in their exposure to violence, which has been identified by governmental and international aid organizations as random and indiscriminate of the target (ECHACP, 2014; Elbert et al., 2013).

Upon arriving at the grocery store, customers were randomly placed into one of two treatments. In both, individuals received a coupon that could be exchanged for 1 bag of flour on the first day it was possible to redeem it. For every day the coupon was saved and not redeemed after the first possible day, it increased in value by another bag (up to 5 bags of flour). In the Immediate treatment, this coupon could be redeemed immediately - customers could redeem it for 1 bag of flour on the same day it was received. In the Delayed treatment, the coupons were only eligible for redemption beginning the following day (the value accrual schedule was thus delayed by a day as well). Thus, the treatment variation enforces a "cooling-off" period in between coupon receipt and the ability to use it. Our main dependent measure was when the coupon was redeemed; whether customers would redeem the coupon earlier for a smaller reward or wait to redeem it for the later, larger reward.

This setting was chosen to minimize potential confounds such as uncertainty about the delivery of a future reward and transaction costs (Benhabib et al., 2010). Due to a lack of access to refrigeration, customers went to the store every morning to buy food for the day, thus controlling for transaction costs associated with redeeming the coupon on the same day versus at a later date. Additionally, participants' frequent interactions with the store and its staff both before and after the study recruitment increased familiarity and minimized uncertainty that future payouts would be delivered. ${ }^{1}$

The vast majority of studies of present bias involve experimenters comparing the choices of individuals when trading off between the present and future versus two dates in the future with the same delay in between. Commitment to follow through on decisions for the future is a feature of the experiment itself. Our design takes a hands-off approach that identifies whether giving individuals extra time to consider their decision affects the choice they make. Rather than offering our subjects commitment to future choices, we offer them the opportunity to seek such commitments themselves. Note that a model of decision making where individuals are either dynamically

\footnotetext{
${ }^{1}$ Measures of trust did not differ by treatment or exposure to violence.
} 
consistent or are naïve about their dynamic inconsistency would predict no difference between the Immediate or Delayed treatments. Our design tests specifically for "sophisticated" present bias, in which individuals are aware that they sometimes make errors in dynamic judgments and seek out commitment devices that would mitigate such errors. In our context, an example would be leaving the coupon at home before going to the store or giving it to a more patient family member until it has accrued the full value. Such present bias would correspond to redeeming the coupon the same day for the smaller amount of flour when it is available immediately and waiting for the larger amount of flour when a cooling-off period is imposed and the immediate choice is not available.

Prior evidence indicates a weak or insignificant relationship between violence and a measure of time preferences, but in those studies all intertemporal choices were only made between options in the future (Bchir and Willinger, 2013; Voors et al., 2012). We find a similar result in that context: those exposed and unexposed to violence are equally patient in waiting for the coupon to accrue value in the Delayed treatment. However, we offer the novel finding that individuals exposed to violence are almost twice as likely to redeem their coupons for the minimum value, right away, in the Immediate treatment. Thus, our unique design identifies a little-studied violation of the invariance property of time preferences (Halevy, 2015), and we show that it is much more common amongst individuals that have suffered directly from conflict in the region.

Given that areas and individuals affected by violence are often targeted with aid and recovery efforts, this evidence should inform the delivery and nature of that aid. Our findings imply that policies designed to help individuals and communities recover from violence should account for increased impulsivity (Bernheim and Rangel, 2007; Camerer et al., 2003). Unconditional cash transfers, which are common in the wake of humanitarian emergencies (ICRC, 2007; Jaspars et al., 2007), offer flexibility and low delivery costs but also great scope for temptation. Farmers in the developing world often face depressed prices at harvest due to the synchronized production cycles for producers (Duflo et al., 2011). Enforcing delays (and perhaps encouraging the use of those delays for planning and budgeting) between cash transfer notifications and consumption opportunities or between crop sales agreements and delivery/payment could allow time inconsistent individuals to seek out opportunities that would allow them to choose when to sell their crops or use their cash transfer in a manner more consistent with their long run interests. Additionally, our results suggest that predatory lenders may consider areas affected by violence to be ripe targets, and hence these 
regions would stand to derive greater benefits from government monitoring and intervention. The results of our study suggests that the optimal policies need not be costly or paternalistic. Rather, they suggest that simply introducing temporal separation between an income notification and the ability to spend it or redeem it leads individuals to make more patient decisions.

The paper is organized as follows. Section 2 reviews the literature on trauma and changes to behavior and preferences. In Section 3 we discuss the procedures and the data, outlining our hypotheses and identification strategy. Section 4 presents results, robustness checks and welfare analysis. Section 5 concludes.

\section{Trauma and Behavioral Change}

Standard economic theory typically takes preferences as exogenous and stable over time. Models of habit formation (Constantinides, 1990) and rational addiction (Becker and Murphy, 1988) acknowledge that people's tastes may evolve with time but changes to preferences are fully anticipated and the time path of preferences is optimally chosen by the individual. For example, a teenager deciding whether to begin to use cigarettes is modeled as being fully aware that his desire for cigarettes will increase the more he smokes. If he chooses to begin smoking, it is only after weighing the costs and benefits of the addiction path. Recent work in both psychology and economics has documented that preferences are in fact malleable, subject to change due to fleeting emotional states (Loewenstein, 1996), visceral factors such as hunger (Danziger et al., 2011; Kuhn et al., 2014) and intoxication (Schilbach, 2015), as well as exogenous events like natural disasters (Eckel et al., 2009).

In the domain of choice under uncertainty, prior events and life experiences drastically change individuals' willingness to take risks. Malmendier and Nagel (2011) demonstrate that experiencing macroeconomic shocks such as the Great Depression significantly affected preferences for risk decades later. The authors find that those who experienced poor returns on stocks are less likely to invest in the stock market and take on financial risk, while those who have lost money on bonds are less likely to participate in the bond market. Natural disasters have also been shown to significantly affect risk preferences, though evidence on the direction is mixed. Eckel et al. (2009) and Bchir and Willinger (2013) show that people negatively impacted by Hurricane Katrina in 
New Orleans and mudslides in Arequipa, Peru, respectively, appear more risk seeking than those who were not impacted. Cameron and Shah (2013) find that individuals who suffered earthquakes and floods in Indonesia become more risk averse than otherwise similar groups in neighboring villages. Evidence on the effects of violence on risk preferences is similarly mixed. While Voors et al. (2012) find that people exposed to violence become more willing to take risk, Callen et al. (2014) find the opposite: that people become more risk averse. ${ }^{2}$

Transient emotional states such as happiness (Ifcher and Zarghamee, 2011) and feelings of loss of control (Gneezy and Imas, 2014) have been shown to have a significant effect on how people make choices over time (for an overview, see Lerner and Loewenstein (2003)). However, evidence on the medium to long run consequences of prior events and experiences on time preferences is mixed. Callen (2015) finds that individuals affected by a tsunami in Sri Lanka become more patient over the long-run. Living in an area where a negative event or violence occurred has a weak (Voors et al., 2012) or insignificant (Bchir and Willinger, 2013) effect on time preferences. These studies measured exposure to violence on the community level, and individuals who may have seen violence indirectly or not at all were classified as exposed. Additionally, they examined time preferences over outcomes that all lay in the future, and in turn could not identify an effect on present bias separate from exponential discounting.

Several lines of work suggest that violence should affect time preference via present bias, where individuals are more likely to choose a smaller, sooner reward over a larger, later reward when the former is available immediately than when both choices are in the future. Callen et al. (2014) demonstrate that rather than increasing risk aversion in general, exposure to a violent act exacerbates the certainty premium -the discontinuity in the valuation of a gamble that occurs as the gamble approaches a certain payment (Kahneman and Tversky, 1979). Indeed, Blumenstock et al. (2014) find that exposure to violence significantly decreases the propensity to use mobile money over cash, which the authors suggest is due to the greater perceived certainty associated with holding physical money. Andreoni and Sprenger (2012a,b) argue that given the inherent certainty in the present and uncertainty in the future, this discontinuity is a contributing factor to impulsivity and present bias. Additionally, exposure to violence has been shown to negatively

\footnotetext{
${ }^{2}$ Several potentially important features distinguish the two studies, such as the fact that Voors et al. (2012) measure exposure to violence on a community level while Callen et al. (2014) measure exposure to violence on the individual level.
} 
impact emotional regulation (Osofsky, 1995), which plays an important role in self-control and impulsivity (Loewenstein, 2000). Given this evidence, we hypothesize that direct exposure to violence affects time preferences by exacerbating present bias.

It should be noted that our use of the term "present bias" to describe the treatment effects that we observe in our study slightly differs from how the term has been used in prior work. Particularly, our design is unique in that we allow no pre-committed choices between future options. In the study, if an individual is not present biased (i.e. has dynamically consistent preferences) or is present biased but is not aware of it (i.e. naiveté), there should be no behavioral differences between the treatments. However, for an individual who is aware of her own susceptibility to impulsive choices (a "sophisticated" present-biased discounter), the Delayed treatment offers a chance to deliberate on how to use the coupon outside of the immediate consumption opportunity. Introducing this cooling-off period allows individuals to seek ways of committing their future selves to wait for the coupon to attain maximum value. As such, our design identifies both present bias and sophistication about the bias together.

Halevy (2015) provides a useful taxonomy of the various types of time inconsistency based on three observed tradeoffs: 1) a tradeoff between the present and future observed in the present, 2) a tradeoff between two dates in the future observed in the present and 3) a tradeoff between two dates in the future observed in the future. Most studies of present bias elicit an inequality between the first two tradeoffs. This is termed a violation of stationarity of preferences. A limited number of studies elicit an inequality between the second and third tradeoffs, termed a violation of consistency of preferences (e.g. Read and van Leeuwen (1998), Read et al. (2012), Sadoff et al. (2015)). This study and Halevy (2015) elicit an inequality between the first and third tradeoffs, termed a violation of invariance of preferences.

\section{Experiment Procedures}

\subsection{Background}

Our study was conducted at a local grocery store in a residential area in Bukavu, a city on the Eastern border of the Democratic Republic Congo (DRC). For more than 20 years, the DRC has 
been facing an ongoing, complex and multifactor militarized conflict. By 2008, the first and second Congo wars and their aftermaths had killed 5.4 million people mostly in the East Congo (Coghlan et al., 2007) and random violence was widespread (Elbert et al., 2013). Despite the UN efforts, including the Goma peace agreements of 2008 and 2009, fighting among various armed groups continues to the present (AI, 2004, 2008a,b, 2012; MSF, 2013).

Since the store is located near an active combat zone, our population is a mix of people with different exposures to violence. We measure exposure to violence at the individual level using a detailed survey completed in a controlled setting. Participants went through a list of scenarios relating to exposure to violence. In our sample, $34 \%$ were directly exposed to violence ("personally injured during the war"), while $66 \%$ were either indirectly exposed to violence ("members of family injured during war") or not exposed at all.

The store is popular among locals and sells everyday goods and simple foodstuffs like rice, water, and milk. A total of 258 customers participated in the study. Because the store has access to electricity and refrigeration, which is lacking in most homes, the vast majority of people in our sample visited the store every day. This is important because it indicates that differences in the imposed transaction costs of the study were likely small across days. That, and our staggered design, allows us to largely rule out transaction costs as important drivers of behavior. The store ran as usual during the study and was staffed by the family that has owned and operated it for the past decade in order to avoid disrupting customers' familiarity with the store and to reduce uncertainty related to the experiment taking place. One of the authors supervised all aspects of the procedures for the entire length of the experiment.

\subsection{Design and Implementation}

Upon arriving at the store and agreeing to participate, all customers completed a detailed survey on their exposure to violence and other demographic measures. Participants who were illiterate or had difficulty completing the survey on their own were helped by a research assistant who was blind to the hypothesis. The survey was in both Swahili and French and the participant chose which was more convenient for them. On average the survey took 30 minutes to complete.

Participants were then randomly assigned to one of two treatments. In both, they received a 
coupon that could be exchanged for varying amounts of flour depending on when it was redeemed. ${ }^{3}$ In the Immediate treatment, the coupon could be redeemed right away for 1 bag of flour (approximately $1 \mathrm{~kg}$ ), the next day for 2 bags of flour, and so on, up until 5 bags of flour. The Delayed treatment shifted the redemption schedule by one day: the first time the coupon could be redeemed was on the next day for 1 bag of flour, and so on, up until 5 bags of flour. The value of the coupon at the time of redemption serves as our measure of time preference. Due to the material incentives and the fact that participants came to the store every day, only one person did not redeem their coupon by the last possible day (this individual was in the Delayed treatment).

\subsection{Identifying Assumptions}

Our identifying assumptions are that assignment to treatment was random and that exposure to violence was conditionally independent of the preferences that drive differences in behavior across treatments. Particularly, although we cannot completely rule out that violence exposure was independent of time preferences (though we provide evidence below suggesting that it was), our primary analysis examines the effect of violence as a difference-in-differences across exposure and treatment, which was randomly assigned. Of the 258 participants, 136 were assigned to the Immediate treatment and 122 to the Delayed treatment. Table 1 presents summary statistics from the questionnaire to verify that key demographic and preference variables are uncorrelated with treatment assignment. The frequency of significant differences is consistent with randomness. ${ }^{4}$ Importantly, neither trust of others, ${ }^{5}$ stated preference for risk, ${ }^{6}$ nor exposure to violence of any type are correlated with treatment assignment.

According to the reports from International Organizations, local NGOs and the US State Department (AI, 2004; Mahecic, 2012; MSF, 2005; USDOS, 2014), the violence perpetrated by armed groups in the region was indiscriminate.

According to a UN Security Council report from 30 September 2013, armed groups were randomly shelling populated areas including camps for internally displaced persons and the airport.

\footnotetext{
${ }^{3}$ Each coupon had an ID matching it with a questionnaire, a date of issue and a code signifying the treatment.

${ }^{4}$ Full questionnaire available upon request.

5 "Generally speaking, would you strongly agree, somewhat agree, somewhat disagree or strongly disagree that most people can be trusted?"

6"Please indicate to what extent you strongly agree, somewhat agree, somewhat disagree, or strongly disagree with the following statement. I am not afraid to take risks."
} 
Table 1: Observable Balance across Treatments

\begin{tabular}{lccc}
\hline \hline Variable & Immediate & Delayed & Difference \\
\hline Female & 0.41 & 0.42 & -0.01 \\
Age & 30.90 & 30.59 & 0.31 \\
Secondary education or beyond & 0.79 & 0.77 & 0.02 \\
Has children & 0.69 & 0.75 & -0.05 \\
Employed & 0.44 & 0.39 & 0.06 \\
Distance from city center (1-3 scale) & 1.57 & 1.61 & -0.04 \\
Feels safe at home (1-4 scale) & 2.34 & 2.53 & $-0.20^{*}$ \\
Access to food (1-4 scale) & 2.39 & 2.39 & 0.00 \\
Access to clean water (1-4 scale) & 2.40 & 2.29 & 0.11 \\
Access to medical care (1-4 scale) & 2.05 & 2.13 & -0.08 \\
Access to shelter (1-4 scale) & 2.36 & 2.40 & -0.04 \\
Access to phone network (1-4 scale) & 2.66 & 2.40 & $0.26^{*}$ \\
Life got better last year (1-5 scale) & 3.04 & 3.14 & -0.10 \\
Expects life better next yr. (1-5 scale) & 3.72 & 3.73 & -0.08 \\
Not afraid to take risks (1-4 scale) & 3.03 & 3.12 & -0.09 \\
Feels in control of life (1-4 scale) & 2.32 & 2.23 & 0.08 \\
Worries about future (1-4 scale) & 2.74 & 2.88 & -0.14 \\
Plans for next week (1-4 scale) & 3.10 & 3.13 & -0.04 \\
Trusts people (1-4 scale) & 2.38 & 2.55 & -0.17 \\
Close to community (1-4 scale) & 2.94 & 3.05 & -0.11 \\
Property damage due to conflict & 0.46 & 0.50 & -0.04 \\
Direct exposure to violence & 0.38 & 0.30 & 0.08 \\
\hline
\end{tabular}

${ }^{* * *} \Rightarrow p<0.01,{ }^{* *} \Rightarrow p<0.05,{ }^{*} \Rightarrow p<0.10$.

According to a Human Rights Watch report (Longman and Kippenberg, 2000), "armed groups indiscriminately attacked civilians and burned houses." The violence was so widespread and perpetrated by such a large number of different forces that victims and witnesses of attacks had difficulty identifying the perpetrators.

In addition to citing the eyewitness and expert classification of the violence as random and controlling for a broad set of economic, demographic and personality variables that could also 
have been affected by violence, we use an instrumental variables approach from the literature for estimating the effect of violence. Voors et al. (2012) use the location of a village relative to the capital city in Burundi as an instrument for exposure to violence during a civil war. We use a similar strategy as a robustness check; given the nature of the source of violence in and around Bukavu we substitute distance from the capital for distance from the city center. The validity of the instrument depends on the assumption that where, within the small area served by the grocery store, individuals choose to live is independent of their level of present bias, conditional on observable controls.

Direct exposure to violence is correlated with other, less direct types of exposure to violence such as seeing violent acts committed against others, narrowly avoiding injury from bombings or shootings, having family members injured, killed or go missing and having close friends injured, killed or go missing. Additionally, it is related to damage, destruction and confiscation of one's home and forced migration. We use property damage as a control variable to rule out loss of wealth as a channel for the relationships we observe.

\section{Results}

We break our results into two subsections. First, we present reduced-form results that characterize the data and effects of the experimental manipulations. Second, we estimate structural discounting parameters to contribute to the growing literature estimating the magnitude of deviation from standard models of time preference and to cast the effects of violence and treatment status in an interpretable and externally relevant metric.

\subsection{Reduced-form Estimates}

First we examine differences in the frequency with which individuals redeem the coupons as soon as possible for their minimum value of 1 bag of flour. There are 34 individuals $(25 \%)$ in the Immediate treatment who redeem the coupon as soon as possible whereas only $11(9 \%)$ do so in the Delayed treatment. The $16 \%$ difference is statistically significant $(p<0.01)$.

The difference in redemption rates for the sooner, smaller reward suggests that individuals in our sample are subject to impulsive behavior that is mitigated by introducing a cooling-off period: 
when given the opportunity to think about their choice for a day, individuals are more likely to allow the coupon to acquire additional value before using it. Instead of simply pushing back the onset of temptation and impulsivity by a day, the delay changed the decision problem such that individuals are able to attain the larger, later reward.

We now examine the interaction between the effect of experimental treatment and stated direct exposure to violence. Using the binary decision of whether to redeem the coupon as soon as possible, Figure 1 shows the effect of treatment broken down into the exposed and unexposed groups. There is a clear and significant difference-in-differences in redemption behavior. The levels of impulsive choice of the exposed and unexposed groups within the Delayed treatment are almost identical ( $8 \%$ unexposed versus $11 \%$ exposed, $p=0.69$ ), but significantly different in Immediate (19\% unexposed versus $35 \%$ exposed, $p=0.01$ ). With the addition of a standard set of demographic, preference and study controls, we estimate a difference between the groups exposed and unexposed to violence of $25 \%$ in the Immediate treatment, while there is only a $4 \%$ difference between groups in the Delay treatment. The $21 \%$ difference in differences is significant at the $5 \%$ confidence level $(p=0.03)$.

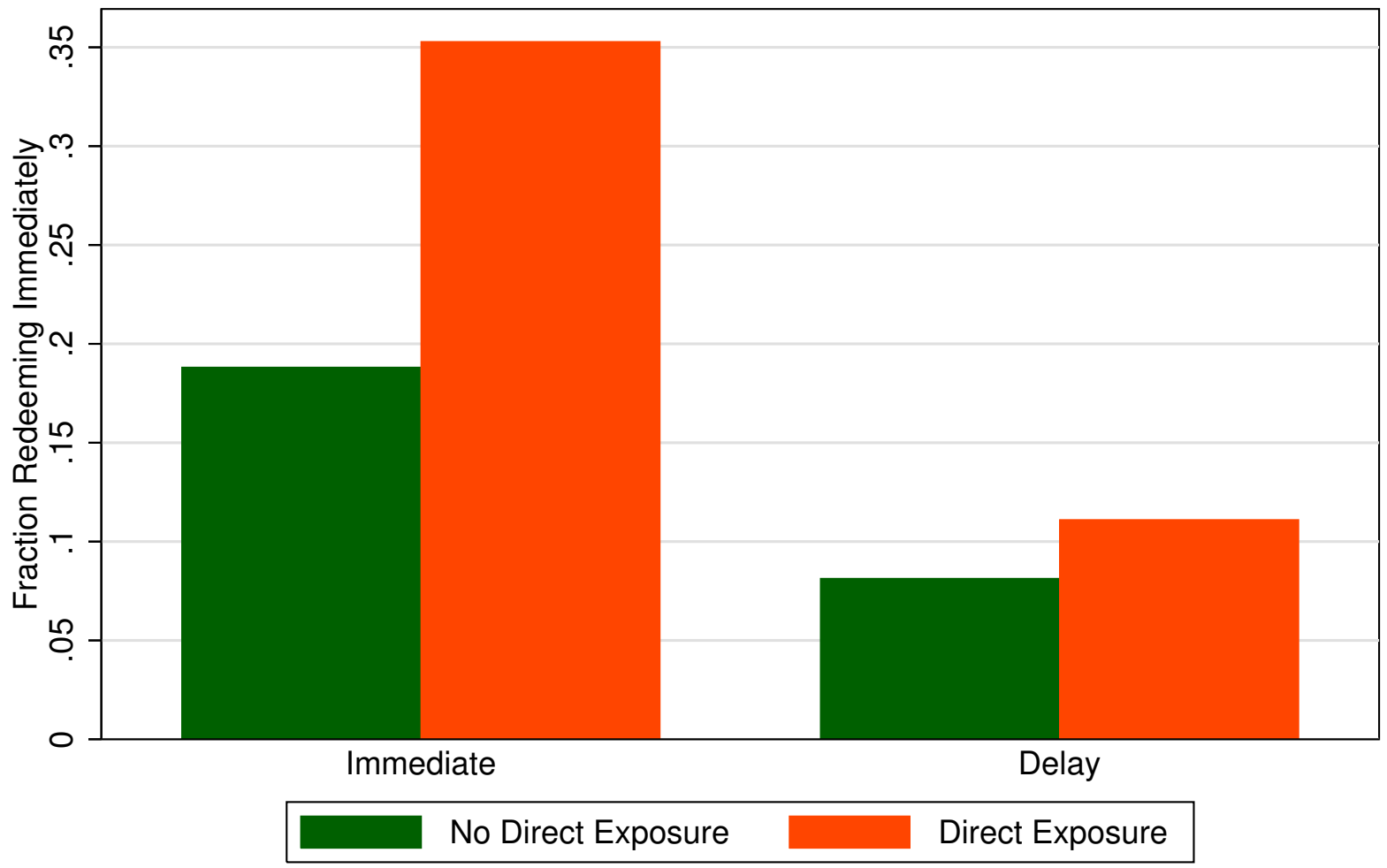

Figure 1: Immediate Redemption by Exposure to Violence and Treatment 
Moving beyond the binary measure, we estimate the relationship between exposure to violence and redemption amount separately for each treatment and then test for a difference between the coefficients. Results are presented in Table 2. We find that exposure to violence in the Immediate treatment corresponds to redeeming the coupons 0.65 days sooner and therefore for 0.65 fewer $\mathrm{kg}$ of flour $(p=0.03)$ without controls and 0.92 days sooner $(p<0.01)$ with controls, relative to those not directly exposed to violence. There is no such link in the Delay treatment: violent exposure prompts coupon use 0.08 days sooner $(p=0.70)$ without controls and 0.18 days sooner $(p=0.38)$ with controls. The difference in differences is significant at $5 \%$ confidence with controls $(p=0.03$; without controls $p=0.11$ ).

Table 2: Redemption Date by Treatment

\begin{tabular}{|c|c|c|c|c|}
\hline & \multicolumn{4}{|c|}{ Treatment } \\
\hline & $\begin{array}{c}\text { Immediate } \\
\text { (1) }\end{array}$ & $\begin{array}{l}\text { Delayed } \\
\text { (2) }\end{array}$ & $\begin{array}{c}\text { Immediate } \\
\text { (3) }\end{array}$ & $\begin{array}{c}\text { Delayed } \\
\text { (4) }\end{array}$ \\
\hline Violence exposure & $\begin{array}{c}-0.65^{* *} \\
(0.28)\end{array}$ & $\begin{array}{l}-0.08 \\
(0.21)\end{array}$ & $\begin{array}{c}-0.92^{* * *} \\
(0.30)\end{array}$ & $\begin{array}{l}-0.18 \\
(0.21)\end{array}$ \\
\hline$H_{0}:$ Immediate $=$ Delay & \multicolumn{2}{|c|}{$\begin{array}{c}\chi^{2}(1)=2.52 \\
p=0.11\end{array}$} & \multicolumn{2}{|c|}{$\begin{array}{c}\chi^{2}(1)=4.58 \\
p=0.03\end{array}$} \\
\hline Male & & & $\begin{array}{c}-0.79^{* *} \\
(0.30)\end{array}$ & $\begin{array}{l}-0.12 \\
(0.21)\end{array}$ \\
\hline Has children & & & $\begin{array}{c}0.04 \\
(0.34)\end{array}$ & $\begin{array}{c}0.26 \\
(0.25)\end{array}$ \\
\hline Employed & & & $\begin{array}{c}0.14 \\
(0.29)\end{array}$ & $\begin{array}{l}-0.06 \\
(0.21)\end{array}$ \\
\hline Risk-loving (0-3 scale) & & & $\begin{array}{c}0.10 \\
(0.15)\end{array}$ & $\begin{array}{l}-0.04 \\
(0.10)\end{array}$ \\
\hline Life control ( $0-3$ scale $)$ & & & $\begin{array}{l}0.31^{* *} \\
(0.13)\end{array}$ & $\begin{array}{l}-0.05 \\
(0.09)\end{array}$ \\
\hline Property damage & & & $\begin{array}{c}0.49 \\
(0.30)\end{array}$ & $\begin{array}{l}0.49^{* *} \\
(0.20)\end{array}$ \\
\hline Constant & $\begin{array}{c}3.67 \\
(0.17)\end{array}$ & $\begin{array}{c}3.30 \\
(0.11)\end{array}$ & $\begin{array}{c}2.87 \\
(0.83)\end{array}$ & $\begin{array}{c}2.99 \\
(0.46)\end{array}$ \\
\hline Day FE & $\mathrm{N}$ & $\mathrm{N}$ & $\mathrm{Y}$ & $\mathrm{Y}$ \\
\hline Observations & 136 & 122 & 128 & 120 \\
\hline
\end{tabular}

Augmenting the regressions of redemption amount on exposure with a more extensive list of 
controls that includes variables such as access to food, clean water, shelter, medical supplies, phone networks and employment status has no effect on the coefficient in the Immediate treatment and leads to a small increase in absolute value of the coefficient in the delay treatment. ${ }^{7}$

As a robustness check we attempt an instrumental variables specification analogous to Voors et al. (2012). They argue that where individuals live is unrelated to their preferences, conditional on the distance to their local market, and show that where individuals live relative to the capital is a predictor of exposure to violence. Our survey collected information on where individuals live: in the city center, outside the city center or in a village outside the city. ${ }^{8}$ In the case of Voors et al. (2012), proximity to the capital was positively correlated with exposure to violence. In our case, proximity to active combat on the outskirts of the city predicts exposure to violence. When we perform the IV estimation, we find that the coefficient on violence in the Immediate treatment becomes considerably larger in absolute value, but that the standard errors are larger, relative to the coefficient magnitude, as well. Results are in Table 3. Exposure is associated with coupon redemption 2.02 days earlier in the Immediate treatment in the baseline model and 2.16 days earlier in the Immediate treatment in the model with controls (the estimate is marginally significant in the latter and not significant at conventional levels in the former). The coefficient on violence in the Delayed treatment insignificant in both cases. ${ }^{9}$ An odd finding is that the relevance of the distance instrument is considerably better in the Immediate treatment than the Delayed treatment, despite the distance and violence variables being almost perfectly balanced across treatments.

In sum, we identify impulsive behavior in our data using experimental treatments, and show that exposure to violence exacerbates impulsivity and present bias by increasing the propensity to redeem the coupon immediately when there is no delay. Exposure reduces the amount of flour obtained using

the coupon by just under $1 \mathrm{~kg}$. The instrumental variables approach we borrow from the literature indicates even larger effects, on the order of $2 \mathrm{~kg}$, although the precision of the estimate is lower.

\footnotetext{
${ }^{7}$ Similarly, the qualitative results from the binary-outcome regressions are unaffected by the inclusion of these controls.

${ }^{8}$ This roughly corresponds to living right by the store, having a 5-10 minute walk to the store or having a 30 minute walk to the store. Because all individuals in our sample share a common market, we cannot condition on distance to market (the store itself).

${ }^{9} \mathrm{An}$ alternative specification for the IV is to use indicators for two of the three distance categories as separate instruments, In this case, we do find a meaningful negative coefficient on violence in the Delayed treatment, although it is not precisely estimated and remains about half the magnitude of the coefficient in the Immediate treatment.
} 
Table 3: Redemption Date by Treatment, IV Models

\begin{tabular}{|c|c|c|c|c|}
\hline & \multicolumn{4}{|c|}{ Treatment } \\
\hline & $\begin{array}{l}\text { Immediate } \\
\text { (1) }\end{array}$ & $\begin{array}{l}\text { Delayed } \\
\text { (2) }\end{array}$ & $\begin{array}{l}\text { Immediate } \\
\text { (3) }\end{array}$ & $\begin{array}{l}\text { Delayed } \\
\text { (4) }\end{array}$ \\
\hline Violence exposure & $\begin{array}{l}-2.07 \\
(1.28)\end{array}$ & $\begin{array}{l}0.83 \\
(7.87)\end{array}$ & $\begin{array}{l}-2.16^{*} \\
(1.21)\end{array}$ & $\begin{array}{l}-0.38 \\
(2.24)\end{array}$ \\
\hline Male & & & $\begin{array}{l}-0.67^{* *} \\
(0.33)\end{array}$ & $\begin{array}{l}-0.13 \\
(0.21)\end{array}$ \\
\hline Has children & & & $\begin{array}{l}0.00 \\
(0.35)\end{array}$ & $\begin{array}{l}0.27 \\
(0.31)\end{array}$ \\
\hline Employed & & & $\begin{array}{l}0.01 \\
(0.32)\end{array}$ & $\begin{array}{l}-0.08 \\
(0.32)\end{array}$ \\
\hline Risk-loving (0-3 scale) & & & $\begin{array}{l}0.11 \\
(0.16)\end{array}$ & $\begin{array}{l}-0.05 \\
(0.15)\end{array}$ \\
\hline Life control (0-3 scale) & & & $\begin{array}{l}0.30^{* *} \\
(0.13)\end{array}$ & $\begin{array}{l}-0.04 \\
(0.11)\end{array}$ \\
\hline Property damage & & & $\begin{array}{l}0.77^{*} \\
(0.40)\end{array}$ & $\begin{array}{l}0.52 \\
(0.40)\end{array}$ \\
\hline Constant & $\begin{array}{l}4.20 \\
(0.50)\end{array}$ & $\begin{array}{l}3.03 \\
(2.34)\end{array}$ & $\begin{array}{l}3.03 \\
(0.66)\end{array}$ & $\begin{array}{l}3.07 \\
(0.97)\end{array}$ \\
\hline Relevance test & $\begin{array}{l}\chi^{2}=7.79 \\
p=0.01\end{array}$ & $\begin{array}{l}\chi^{2}=0.10 \\
p=0.76\end{array}$ & $\begin{array}{l}\chi^{2}=8.34 \\
p<0.01\end{array}$ & $\begin{array}{l}\chi^{2}=0.98 \\
p=0.32\end{array}$ \\
\hline Day FE & $\mathrm{N}$ & $\mathrm{N}$ & $\mathrm{Y}$ & $\mathrm{Y}$ \\
\hline Observations & 136 & 121 & 128 & 120 \\
\hline
\end{tabular}

${ }^{* * *} \Rightarrow p<0.01,{ }^{* *} \Rightarrow p<0.05,{ }^{*} \Rightarrow p<0.10$.

We do not find a significant relationship between violence and behavior in the Delayed treatment. This suggests that violence exacerbates impulsivity when the smaller, sooner reward is available immediately rather than time discounting between all periods, which is indicative of greater present bias.

\subsection{Structural Estimates}

A common approach to characterizing the severity of impulsive behavior is to estimate the parameters of an intertemporal utility function that allows for deviations from time-consistent planning. As discussed earlier, we focus on the $\beta-\delta$ formulation from Laibson (1997) and O'Donoghue and 
Rabin (1999). The utility function associated with consumption at time $t$ from the point of view of period 0 is

$$
U\left(c_{t}\right)=\beta^{1(t=0)} \delta^{t} u\left(c_{t}\right)
$$

where $u\left(c_{t}\right)$ is the instantaneous consumption utility function. For now, we assume that $u\left(c_{t}\right)=c_{t}$ and present estimates for alternative specifications at the end of the section. The key deviation from classic exponential discounting is that the $\beta$ parameter matters only when comparing consumption in the present period to consumption in a later period.

In the context of our study, when $\beta<1$ (present-bias), an individual in the Immediate treatment is more likely to choose to consume at the first opportunity than they would be in the Delay treatment when they have access to potential commitment devices such as leaving the coupon at home or conferring it to a family member. This is true regardless of the exponential discount factor, $\delta$. An individual with $\delta=1$ would wait the maximum possible time in the Delay treatment to redeem. If they were present biased, the only possible effect of moving them to the Immediate treatment would be to move them to immediate redemption option. Hence the emphasis on the fraction of individuals choosing the soonest-possible redemption in both treatments: under specific assumptions, comparing these statistics leads directly to an estimate of $\beta$.

We use a random-utility model to estimate $\beta$ from the binary data on soonest-possible redemption. The unobserved value an individual $i$, gets from choice option $j$, is

$$
V_{i, j}\left(c_{j}\right)=U\left(c_{j}\right)+\epsilon_{i, j}
$$

where $c_{j}$ is the consumption value associated with kilograms of flour $j$ and $U(\cdot)$ is the observed utility function, for which we use the intertemporal formulation in (1).

Initially, we assume that individuals only compare redeeming as soon as possible to redeeming as late as possible. Given our assumption of constant marginal utility, in the Immediate treatment this means comparing $1+\epsilon_{i, 1}$ to $5 \beta \delta^{4}+\epsilon_{i, 5}$. When we model choice in the Delayed treatment, we assume that individuals make choices without being subject to present bias. This interpretation is consistent with the supposition that sophisticated individuals will find ways to avoid present bias in this treatment by either seeking out commitment devices in their environment or approaching the decision from a "cold" rather than a "hot" state. Note that our reduced form results support this 
assumption: both a model with time consistent preferences and a model with naiveté about time inconsistency predict no difference between treatments. On a more pragmatic level, the assumption implies that we are using $\beta$ as a way to measure the differences in behavior across treatments, and it will have a prescriptive meaning as the treatment effect regardless of its theoretical interpretation.

Thus, individuals in Delayed will choose the soonest possible redemption if $1+\epsilon_{i, 1}>5 \delta^{4}+\epsilon_{i, 5}$. The probability of this is

$$
\operatorname{Pr}\left(1+\epsilon_{i, 1}>5 \delta^{4}+\epsilon_{i, 5}\right)=\operatorname{Pr}\left(\epsilon_{i, 5}-\epsilon_{i, 1}<1-5 \delta^{4}\right)=F\left(1-5 \delta^{4}\right)
$$

where $F(\cdot)$ is the CDF of the difference in epsilon terms.

In order to identify $\beta$ as a simple statistic from the data, we assume that the difference distribution is uniform on the interval $[-1,1]$. Thus, $F(x)=\frac{x+1}{2}$ and $\operatorname{Pr}\left(c_{i}=1\right)=\frac{2-5 \delta^{4}}{2}$. Call $z_{D}$ the observed frequency of soonest-possible choice in the Delayed treatment. Matching this to the structural probability gives

$$
z_{D}=\frac{2-5 \delta^{4}}{2} \Rightarrow \delta=\left(\frac{2}{5}\left(1-z_{D}\right)\right)^{\frac{1}{4}}
$$

The next step is to derive this probability for the Immediate treatment. The probability of redeeming immediately is

$$
\operatorname{Pr}\left(1+\epsilon_{i, 1}>5 \beta \delta^{4}+\epsilon_{i, 5}\right)=\operatorname{Pr}\left(\epsilon_{i, 5}-\epsilon_{i, 1}<1-5 \beta \delta^{4}\right)=F\left(1-5 \beta \delta^{4}\right) \quad,
$$

which can be matched to $z_{I}$, the observed frequency of soonest-possible choice in the Immediate treatment, yielding

$$
z_{I}=\frac{2-5 \beta \delta^{4}}{2} \Rightarrow \beta=\frac{2}{5}\left(\frac{1-z_{I}}{\delta^{4}}\right)=\frac{1-z_{I}}{1-z_{D}}
$$

A key feature of the expression for $\beta$ is that one arrives at this result regardless of which binary alternative to the soonest-possible redemption choice is used. Table 4 presents the results using this simple method. The estimated present-bias parameters are well within the range established in previous literature, and show a substantial, economically significant gulf between those with and without direct exposure to violence: 0.73 for those directly exposed and 0.88 for those not directly 
exposed to violence. Estimates of $\delta$ are similar for both groups and demonstrate very high rates of discounting. Extrapolating from short-horizon estimates such as these

Table 4: Discounting Parameter Estimates from Binary Choice Model

\begin{tabular}{|c|c|c|c|c|c|}
\hline & \multicolumn{5}{|c|}{ Estimated Utility Parameter } \\
\hline & \multirow[t]{3}{*}{$\beta$} & \multicolumn{4}{|c|}{$\delta$} \\
\hline & & \multicolumn{4}{|c|}{$\delta$ delay (days) } \\
\hline & & 1 & 2 & $3^{\dagger}$ & $4^{\dagger \dagger}$ \\
\hline Constant (unexposed) & $\begin{array}{c}0.88 \\
(0.06)\end{array}$ & $\begin{array}{c}0.92 \\
(0.04)\end{array}$ & $\begin{array}{c}0.78 \\
(0.02)\end{array}$ & $\begin{array}{c}0.77 \\
(0.01)\end{array}$ & $\begin{array}{c}0.78 \\
(0.01)\end{array}$ \\
\hline Direct exposure to violence? & $\begin{array}{l}-0.16 \\
(0.10)\end{array}$ & $\begin{array}{l}-0.03 \\
(0.07)\end{array}$ & $\begin{array}{l}-0.01 \\
(0.03)\end{array}$ & $\begin{array}{l}-0.01 \\
(0.02)\end{array}$ & $\begin{array}{l}-0.01 \\
(0.02)\end{array}$ \\
\hline
\end{tabular}

${ }^{* * *} \Rightarrow p<0.01,{ }^{* *} \Rightarrow p<0.05,{ }^{*} \Rightarrow p<0.10$. The different specifications of the $\delta$ delay refer to which later option we use as the alternative to soonest-possible redemption in the binary choice specification. ${ }^{\dagger}$ The modal choice, other than soonest possible redemption, in the Delayed treatment was to wait 3 days to redeem the coupon. ${ }^{\dagger \dagger}$ The modal choice, other than soonest possible redemption, in the Immediate treatment was to wait 4 days to redeem the coupon. This means that the estimate of $\delta$ is a lower bound due to the censoring at this point.

to characterize long-horizon interest rate preferences is unlikely to be informative, as noted in many similar studies.

The distributional assumptions required for such a simple estimation of the discounting parameters are highly specific. For that reason, we now take an approach with identification founded in the first-order condition of a non-binary utility maximization problem. Consider that an individual choosing when to redeem their coupon is trading off between the amount they receive and when they receive it. Calling the value of the coupon $c$, this means that an individual in the Delay treatment is solving

$$
\max _{t, c} U(t, c)=\delta^{t} c \quad \text { such that } \quad c=t+1 \quad \text { and } \quad 0 \leq t \leq 4
$$

Substituting in the constraint and taking a log expansion yields

$$
\max _{t} \ln (U(t))=t \cdot \ln (\delta)+\ln (t+1) \quad \text { such that } \quad 0 \leq t \leq 4,
$$

with first-order conditions

$$
\ln (\delta)+\frac{1}{t+1}=0 \Rightarrow t^{*}=\frac{-1}{\ln (\delta)}-1
$$


so long as the solution is interior $\left(t^{*}=0\right.$ if $\delta<e^{-1}, t^{*}=4$ if $\left.\delta>e^{\frac{-1}{5}}\right)$. Thus, an estimate of $\delta$ will be obtained as a non-linear combination of the average choice of $t$ in the Delay treatment.

We use the solution above to develop an estimation strategy for $\beta$. First, we note that the maximization problem is slightly different in the Immediate group:

$$
\max _{t, c} \quad U(t, c)=\beta^{1(t>0)} \delta^{t} c \quad \text { such that } \quad c=t+1 \quad \text { and } \quad 0 \leq t \leq 4
$$

Conditional on $\delta$, which we estimate using a tobit procedure to deal with the experimentally imposed bounds on $t$, there exists a most preferred redemption date. Introducing present bias is akin to setting up a binary choice problem between that most preferred date and immediate redemption (if they differ). Specifically, we can plug the solution, (9) back into the log expansion of (10) to get

$$
\ln \left(U\left(t^{*}\right)\right)=\ln (\beta)-\ln (\delta)-\ln (-\ln (\delta))-1
$$

which represents the utility obtained if the individual is constrained away from immediate redemption. If immediate redemption is chosen, then $\ln (U(0))=0$. Therefore, an individual chooses to redeem immediately if

$$
\ln (\beta)-\ln (\delta)-\ln (-\ln (\delta))-1<0
$$

We rearrange (12) for the purposes of estimation to get that individuals redeem immediately if

$$
\delta \cdot \ln (\delta)<\frac{-\beta}{e}
$$

We assume that the population mean of $\delta$ is observed with error, thus leading to an expression for the immediate choice probability

$$
\operatorname{Pr}\left(t^{*}=0\right)=\operatorname{Pr}\left(\delta \cdot \ln (\delta)+\epsilon<\frac{-\beta}{e}\right)
$$

We note that the left side of the inequality in (13) is bounded by the theoretical restriction that $\delta \in[0,1]$. This implies that $\delta \cdot \ln (\delta) \in\left[\frac{-1}{e}, 0\right]$. Therefore, in the case of $\epsilon$ being normally distributed, we impose a standard deviation such that $99 \%$ of its realizations leave the left side within that interval. We also use a uniformly distributed $\epsilon$, with strict bounds placed such that all 
realizations imply the left side obeys the theoretical range. Estimates of $\beta$ using these approaches are reported in columns (1) and (2) of Table 5.

We also take an approach that uses both the estimate of the mean and standard deviation of $\delta$ in the population from the Delay treatment. Using the mean and standard deviation, we simulate the distribution of $\delta \cdot \ln (\delta)$, which becomes the driving random variable. ${ }^{10}$ This approach presumes that the variable observed with a simple error distribution is $\delta$ rather than $\delta \cdot \ln (\delta)$, which was used in the earlier approach for simplicity. To translate the simulated distribution back to the maximum likelihood estimation, we fit it using a flexible, two parameter Beta distribution (we use "Beta" to distinguish the distribution from the parameter of interest), and use it in the log-likelihood function

$$
l(\beta)=\sum_{i} 1\left(t_{i}^{*}=0\right) \cdot \ln (B(-\beta))+\left(1-1\left(t_{i}^{*}=0\right)\right) \cdot \ln ((1-B(-\beta))),
$$

where $B(\cdot)$ is the $\mathrm{CDF}$ of the Beta distribution used to approximate the $\delta \cdot \ln (\delta)$ distribution, and the argument of the CDF is simplified to $-\beta$ by a transformation of the inequality in (13) that puts the data in the support of the beta distribution. Results using this approach, with normal and uniform assumptions on the error in $\delta$ are reported in columns (3) and (4) of Table 5.

The gap between the exposed and unexposed groups indicates that the reduced-form treatment effects correspond to large differences in dynamic inconsistency. The magnitude of the effect varies across the standard deviation specifications, but this is a result of fluctuations of the estimate of $\beta$ for unexposed group, while the estimate for the exposed group remains relatively stable. The difference is always significant at the $5 \%$ confidence level and the size of the gap is substantial. While it appears that unexposed individuals do exhibit present bias of some degree, the level shifts considerably: $\beta$ ranges from 0.96 to 0.74 . For individuals exposed to violence, $\beta$ is much further from 1 and moves around less: $\beta$ ranges from 0.76 to 0.67 . We characterize the impact on decision making of such values of $\beta$ in the following section.

One primary issue of robustness has to do with the maintained assumption in the previous section that individuals' utility in flour is linear. Previous work demonstrates that if this assumption is incorrect, it can bias the estimates of the discounting parameters (Andersen et al., 2008). While we are primarily concerned with the difference in estimates of $\beta$ across groups, the magnitude of the

\footnotetext{
${ }^{10}$ For this simulation, we use both the assumptions of normality and uniformity of $\delta$ about its mean, with results presented for both approaches
} 
Table 5: Estimates of $\beta$ from Convex Models

\begin{tabular}{l}
\hline \hline \\
\cline { 3 - 6 }
\end{tabular}

deviation of the estimates from one is important for weighing the importance of observed present bias. While utility curvature is not separately identified from $\delta$ in the data, we present results from the re-estimation of the convex model from Column (1) of Table 5 assuming an instantaneous utility function of the form $u(c)=c^{\alpha}$. Results are in Table 6 .

All specifications feature a significant difference between the individuals who were or were not directly exposed to violence. This is unsurprising since decreasing $\alpha$ from one (increasing curvature) is just a mechanical re-scaling of the estimates towards one; diminishing marginal utility lowers the returns to growth in the value of the coupon over time. Even assuming extremely rapid diminishing marginal utility, the magnitude of the effect of exposure to violence on present bias is quite meaningful.

Importantly, the only differences in discounting we observe between exposed and unexposed individuals has to do with present bias and not standard discounting, reconciling our finding with the prior literature which has

found only marginal to insignificant effects of violence on time preferences.

\subsection{Welfare Analysis}

A central question in the behavioral economics literature on non-standard time preferences is whether the welfare effects of policies that limit choice biases are a) substantial and b) measurable. The second question is an issue of debate and is outside the scope of the current paper. We 
Table 6: Estimates of $\beta$ from Convex Model, with Varying Utility Curvature

\begin{tabular}{lccccc}
\hline \hline & \multicolumn{6}{c}{$\alpha$} \\
\cline { 2 - 6 } & 0.90 & 0.70 & 0.50 & 0.30 & 0.10 \\
\hline Constant (unexposed) & 0.96 & 0.97 & 0.99 & 1.03 & 1.09 \\
& $(0.06)$ & $(0.05)$ & $(0.04)$ & $(0.03)$ & $(0.02)$ \\
Direct exposure to violence? & $-0.18^{* *}$ & $-0.15^{* *}$ & $-0.12^{* *}$ & $-0.10^{* *}$ & $-0.08^{* *}$ \\
& $(0.08)$ & $(0.07)$ & $(0.06)$ & $(0.05)$ & $(0.04)$ \\
\hline
\end{tabular}

${ }^{* * *} \Rightarrow p<0.01,{ }^{* *} \Rightarrow p<0.05,{ }^{*} \Rightarrow p<0.10$. All models mimic the specification from Column (1) of Table 5, in which we assume errors in $\delta \cdot \ln (\delta)$ are normally distributed with a standard deviation such that $99 \%$ of realizations lies within the interval implied by $\delta \in[0,1]$.

perform a straightforward calculation of the value that an individual, free of their bias, would associate with moving from the outcome when the smaller, sooner reward is available immediately upon learning of it (Immediate treatment) to their optimal choice with a delay between the information and the ability to attain the reward (Delayed treatment), remembering that this decreases the overall value of all rewards by shifting them into the future. In other words, we calculate a compensating variation associated with a policy move from Delay to Immediate, showing results for a range of parameter values that encompass our estimates. Figure 2 shows a graphical interpretation of this measurement. Parameters that generate the figure are chosen for visual clarity and are not based on those from the previous section.

We cannot calculate the estimate directly from the utility parameters because our estimates of $\beta$ come from a model of probabilistic choice. The result is that the indifference curve for the average individual in the Immediate treatment associated with a utility level of 1 (immediate redemption) intersects the Immediate treatment budget (non-tangentially). This is to say that the average individual is not present-biased enough to redeem immediately. Therefore, we downweight the welfare loss associated with assuming immediate redemption by the probability that an individual with the average $\beta$ chooses to redeem immediately. This comes directly from the model of probabilistic choice in (14). Table 7 presents the welfare calculation exercise for a variety of utility parameter specifications that correspond to the results in Tables 4 and 5. Along with the probability weighted welfare loss, the table presents the calibrated probability of choosing immediate redemption in the Immediate treatment, the optimal choice in the Delayed treatment and the utility of that choice on day 0 , which, from the linear utility assumption, is measured in terms of bags of flour, and is thus also equal to the day 0 indirect demand for flour at $U\left(t^{*}\right)$. 


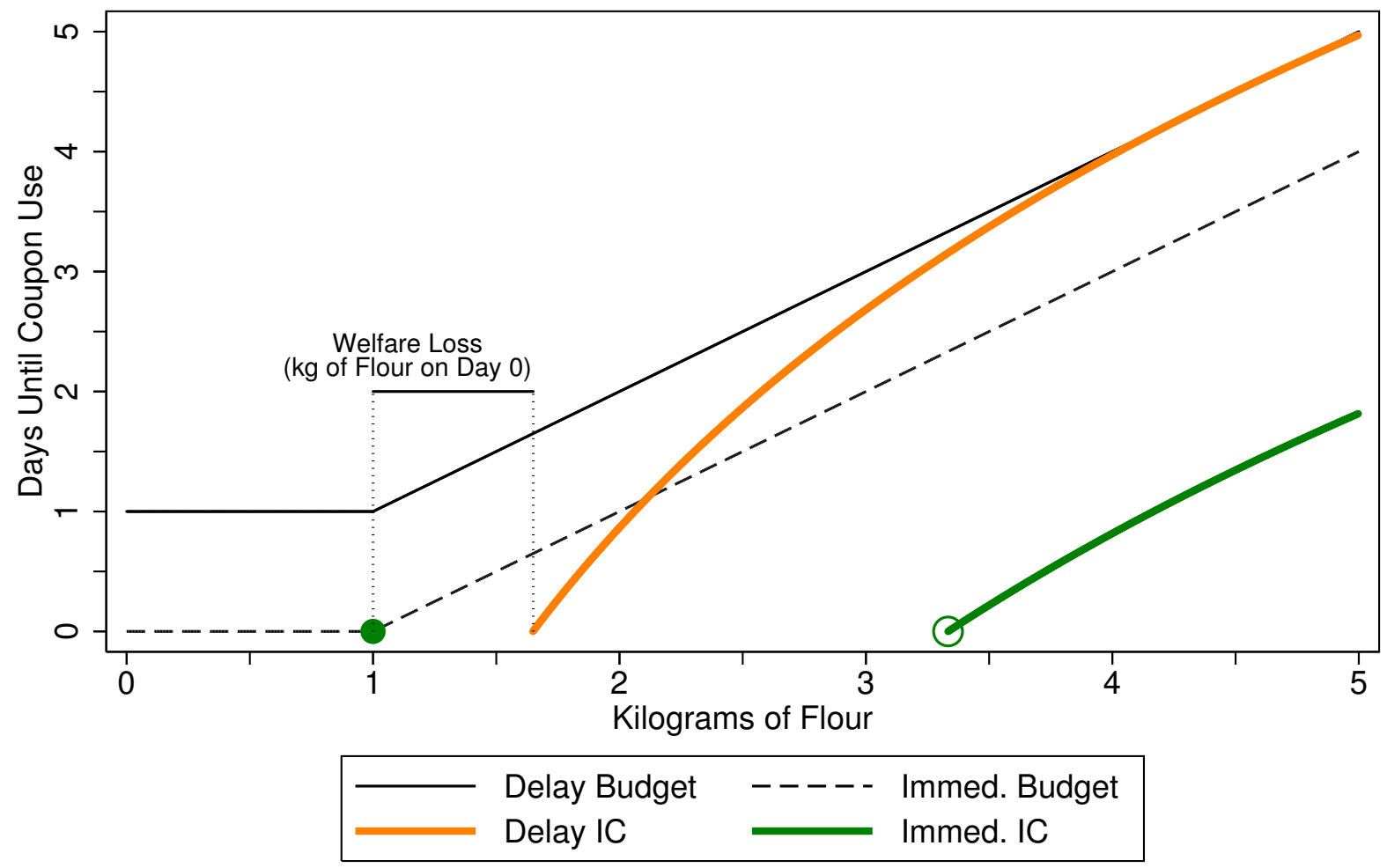

Figure 2: Measuring Welfare Loss due to the Immediate Treatment

The range of estimates for the unexposed group is almost entirely smaller than the range of estimates for the exposed group, with only one instance of overlap. The best match for the unexposed group indicates that an individual values their choice in the Delay treatment at $1.90 \mathrm{~kg}$ of flour on day 0 . The probability of forgoing that for $1 \mathrm{~kg}$ is 0.18 , generating an average loss of 0.16 $\mathrm{kg}$. The best match for the exposed group indicates that an individual values their choice in the Delay treatment at $1.76 \mathrm{~kg}$ of flour on day 0 . This is slightly lower than for the unexposed group because of the difference in $\delta$ values. The probability of forgoing that for $1 \mathrm{~kg}$ is 0.34 , generating an average loss of $0.26 \mathrm{~kg}$. While exposed individuals are losing slightly less by making impulsive choices, they are much more likely to do so. Put another way, the lost welfare in Immediate is almost twice as large for the exposed group as a percentage of the welfare they would have obtained in Delayed: $15 \%$ vs. $8 \%$. An informal translation of $\mathrm{kg}$ of flour to loaves of bread puts the welfare loss for those exposed to violence at just over one loaf. ${ }^{11}$

\footnotetext{
${ }^{11}$ Assuming 2 cups of flour in a loaf, and that one cup of flour weighs 120 grams.
} 
Table 7: Welfare Loss - Compensating Variation for Immediate Availability

\begin{tabular}{lcccccc}
\hline \hline Group, Model & $\beta$ & $\delta$ & $t^{*}$ & $c_{0}=U\left(t^{*}\right)$ & $\operatorname{Pr}\left(t^{*}=0\right)$ & $\operatorname{Pr}\left(t^{*}=0\right) \cdot\left(1-c_{0}\right)$ \\
\hline Unexposed, Binary & & & & & & \\
& 0.88 & 0.92 & 4 & 3.58 & 0.04 & -0.11 \\
& 0.88 & 0.78 & 3.02 & 1.90 & 0.18 & $-0.16^{\dagger}$ \\
Unexposed, Convex & 0.88 & 0.77 & 2.83 & 1.83 & 0.20 & -0.16 \\
& & & & & & -0.12 \\
Exposed, Binary & 0.96 & 0.74 & 2.32 & 1.65 & 0.18 & -0.17 \\
& 0.85 & 0.74 & 2.32 & 1.65 & 0.26 & -0.24 \\
& 0.74 & 0.74 & 2.32 & 1.65 & 0.36 & -0.27 \\
Exposed, Convex & & & & & & -0.26 \\
& 0.73 & 0.89 & 4 & 3.14 & 0.12 & $-0.26^{\dagger \dagger}$ \\
& 0.73 & 0.77 & 2.83 & 1.83 & 0.32 & -0.22 \\
& 0.73 & 0.76 & 2.64 & 1.76 & 0.34 & -0.24 \\
& & & & & & -0.27 \\
\hline
\end{tabular}

${ }^{* * *} \Rightarrow p<0.01,{ }^{* *} \Rightarrow p<0.05,{ }^{*} \Rightarrow p<0.10 .{ }^{\dagger}$ This set of utility parameters generates estimates of the probability of someone unexposed to violence choosing immediate redemption in the Immediate treatment that are the closest among the set to the observed frequency $(0.19)$. $\dagger \dagger$ This set of utility parameters generates estimates of the probability of someone exposed to violence choosing immediate redemption in the Immediate treatment that are the closest among the set to the observed frequency $(0.35)$.

\section{Conclusion}

We summarize the results of our study with three empirical findings. First, imposing a delay (cooling off period) between distributing the coupons and when they could be redeemed led to a considerable increase in the amount of flour the coupons were redeemed for. This is suggestive of sophisticated present bias, in which individuals that are aware of their tendency to act impulsively can overcome it if given an opportunity to seek a commitment device. Second, when rewards are available immediately, redemption of the coupon is much more common amongst individuals who have been directly exposed to violence than those who have not. Third, when rewards are not available immediately, the difference between individuals who have been directly exposed to violence and those who have not disappears: both groups redeem coupons for approximately the same amounts of flour. We argue that the difference in differences provides evidence for a causal effect of violence on time preferences. Results from our structural estimation suggest that the differences induced by exposure to violence can have significant negative welfare consequences, 
and that the magnitudes of present biased exhibited in our study are on the larger side of (but well within) the range established in prior work.

Unlike past experimental work on present bias, individuals in our study did not make binding decisions about when to use the coupons at the time they received them. In other words, we allowed for the possibility that in the Delay treatment individuals would wake up on the day after receipt and impulsively decide to redeem their coupons immediately. This did not happen. Instead, the individuals who had to wait a day before the coupon was redeemable waited until it was much more valuable to do so. Following the taxonomy of Halevy (2015), this suggests a violation of the invariance property of time preferences, an aspect of dynamic inconsistency that has rarely been studied in the past.

The propensity of such violations, which can theoretically stymie the accumulation of human capital and assets, may be increased for people who have undergone traumatic experiences. However, our results suggest that simply giving exposed individuals time to seek commitment devices, assistance, advice from family, or to engage in a more deliberative thought process is remarkably successful at changing their choices to be more patient. The importance of a cooling off period may extend to other important financial decisions. Consider a tax preparer that offers loans against the refunds they calculate. Individuals are notified of their refund and given an opportunity to convert it into consumption simultaneously. A policy that enforced temporal separation between the events would allow sophisticated individuals to protect themselves from offers of predatory interest rates. 


\section{References}

AI. Congo (the democratic republic of), 2004. Amnesty International Annual Report, May 26 2004.

AI. Human rights in democratic republic of the congo, 2008a. Amnesty International Annual Report, May 282008.

AI. Democratic republic of congo: Crisis of north kivu, 2008b. Amnesty International Press Release, November 212008.

AI. Democratic republic of the congo, 2012. Amnesty International Annual Report, May 242012.

S. Andersen, G.W. Harrison, M.I. Lau, and E.E. Rutström. Eliciting risk and time preferences. Econometrica, 76(3):583-618, 2008.

J. Andreoni and C. Sprenger. Estimating time preferences from convex budgets. American Economic Review, 102(7):3333-3356, 2012a.

J. Andreoni and C. Sprenger. Risk preferences are not time preferences. American Economic Review, 102(7):3357-3376, 2012b.

N. Augenblick, M. Niederle, and C. Sprenger. Working over time: Dynamic inconsistency in real effort tasks. NBER Working Paper \#20788, 2013.

M.A. Bchir and M. Willinger. Does the exposure to natural hazards affect risk and time preferences? some insights from a field experiment in perú. RePEc Working Paper \#13-04, 2013.

G.S. Becker and K.M. Murphy. A theory of rational addiction. Journal of Political Economy, 96 (4):675-700, 1988.

J. Benhabib, A. Bisin, and A. Schotter. Present-bias, quasi-hyperbolic discounting, and fixed costs. Games and Economic Behavior, 69(2):205-223, 2010.

B.D. Bernheim and A. Rangel. Toward choice-theoretic foundations for behavioral welfare economics. American Economic Review, 97(2):464-470, 2007. 
Joshua Blumenstock, Michael Callen, and Tarek Ghani. Violence and Financial Decisions: Evidence from Mobile Money in Afghanistan. mimeo, 2014.

J.A. Boscarino. External-cause mortality after psychological trauma: The effects of stress exposure and predisposition. Comprehensive Psychiatry, 47(6):503-514, 2006.

M. Callen. Catastrophes and time preference: Evidence from the indian ocean earthquake. Journal of Economic Behavior and Organization, 2015. Forthcoming.

M. Callen, M. Isaqzadeh, J.D. Long, and C. Sprenger. Violence and risk preference: Experimental evidence from afghanistan. American Economic Review, 104(1):123-148, 2014.

C. Camerer, S. Issacharoff, G. Loewenstein, T. O’Donoghue, and M. Rabin. Regulation for conservatives: Behavioral economics and the case for "asymmetric paternalism". University of Pennsylvania Law Review, 151(3):1211-1254, 2003.

L. Cameron and M. Shah. Risk-taking behavior in the wake of natural disasters. NBER Working Paper \#19534, 2013.

B. Coghlan, P. Ngoy, F. Mulumba, C. Hardy, V. Nkamgang Bemo, T. Stewart, J. Lewis, and R. Brennan. Mortality in the democratic republic of congo: An ongoing crisis, 2007. International Rights Committee.

G.M. Constantinides. Habit formation: a resolution of the equity premium puzzle. Journal of Political Economy, 98(3):519-543, 1990.

S. Danziger, J. Levav, and L. Avanaim-Pesso. Extraneous factors in judicial decisions. Proceedings of the National Academy of Sciences, 108(17):6889-6892, 2011.

S. DellaVigna and U. Malmendier. Paying not to go to the gym. American Economic Review, 96 (3):694-719, 2006.

T. Dohmen, A. Falk, D. Huffman, and U. Sunde. Are risk aversion and impatience related to cognitive ability? American Economic Review, 100(3):1238-1260, 2010.

E. Duflo, M. Kremer, and J. Robinson. Nudging farmers to use fertilizer: Theory and experimental evidence from kenya. American Economic Review, 101(6):2350-2390, 2011. 
ECHACP. Democratic republic of congo: Echo factsheet, 2014. European Commission - Humanitarian Aid and Civil Protection ECHO Factsheet, September 2014.

C.C. Eckel, M.A. El-Gamal, and R.K. Wilson. Risk loving after the storm: A bayesian-network study of hurricane katrina evacuees. Journal of Economic Behavior and Organization, 69(2): 110-124, 2009.

T. Elbert, H. Hinkel, A. Maedl, K. Hermenau, T. Hecker, M. Schauer, M. Riedke, N. Winkler, and P. Lancaster. Sexual and gender-based violence in the kivu provinces of the democratic republic of congo: Insights from former combatants, 2013. Learning on Gender and Conflict in Africa.

S. Frederick, G. Loewenstein, and T. O’Donoghue. Time discounting and time preference: A critical review. Journal of Economic Literature, 40(2):351-401, 2002.

A. Gneezy and A. Imas. Poverty traps and the effect of helplessness on impatience and risk seeking: Evidence from the lab and field. Working Paper, 2014.

Y. Halevy. Time consistency: Stationarity and time invariance. Econometrica, 83(1):335-352, 2015.

ICRC. Guidelines for cash transfer programming, 2007. International Committee of the Red Cross and International Federation of Red Cross and Red Crescent Societies.

J. Ifcher and H. Zarghamee. Happiness and time preference: The effect of positive affect in a random-assignment experiment. American Economic Review, 101(7):3109-3129, 2011.

S. Jaspars, P. Harvey, C. Hudpseth, and L. Rumble. A review of unicef's role in cash transfers to emergency affected populations, 2007. UNICEF EMPOS Working Paper.

D. Kahneman and A. Tversky. Prospect theory: An analysis of decision under risk. Econometrica, 47(2):263-291, 1979.

M.A. Kuhn, P. Kuhn, and M. Villeval. Self control and intertemporal choice: Evidence from glucose and depletion interventions. CESifo Working Paper \#4609, 2014.

D. Laibson. Golden eggs and hyperbolic discounting. Quarterly Journal of Economics, 112(2): 443-477, 1997. 
J.S. Lerner and G. Loewenstein. The role of affect in decision-making. In R. Davidson, K.R. Scherer, and H.H. Goldsmith, editors, Handbook of Affective Science, pages 619-642. Oxford University Press, 2003.

G. Loewenstein. Out of control: visceral influences on behavior. Organizational Behavior and Human Decision Processes, 65(3):272-292, 1996.

G. Loewenstein. Emotions in economic theory and economic behavior. American Economic Review, 90(2):426-432, 2000.

T. Longman and J. Kippenberg. Indiscriminate attacks and extrajudicial executions of civillians, 2000. Human Rights Watch Africa Division Report.

A. Mahecic. Unhcr shocked by abuse of congolese civilians as fighting persists, 2012. United Nations High Commissioner for Refugees, July 272012.

U. Malmendier and S. Nagel. Depression babies: Do macroeconomic experiences affect risktaking? Quarterly Journal of Economics, 126(1):373-416, 2011.

S. Meier and C. Sprenger. Present-biased preferences and credit card borrowing. American Economic Journal: Applied Economics, 2(1):193-210, 2010.

MSF. Msf international president raises alarm over mass rape and violence in the ituri region of $\mathrm{dr}$ congo, 2005. Medecins Sans Frontieres Press Release, April 72005.

MSF. Drc: Msf treats survivors of attack on village in north kivu, 2013. Medecins Sans Frontieres Press Release, May 152013.

T. O’Donoghue and M. Rabin. Doing it now or later. American Economic Review, 89(1):103-124, 1999.

J.D. Osofsky. The effect of exposure to violence on young children. American Psychologist, 50 (9):782-788, 1995.

Daniel Read and Barbara van Leeuwen. Predicting Hunger: The Effects of Appetite and Delay on Choice. Organizational Behavior and Human Decision Processes, 76(2):189-205, 1998. 
Daniel Read, Shane Frederick, and Mara Airoldi. Four days later in Cincinnati: Longitudinal tests of hyperbolic discounting. Acta Psychologica, 140(2):177-185, 2012.

Sally Sadoff, Anya Samek, and Charles Sprenger. Dynamic Inconsistency in Food Choice: Experimental Evidence from a Food Desert. mimeo, 2015.

F. Schilbach. Alcohol and self control: A field experiment in india. Working Paper, 2015.

F. Stewart. War and underdevelopment: Can economic analysis help reduce the costs? Journal of International Development, 5(4):357-380, 1993.

USDOS. Democratic republic of the congo travel warning, 2014. U.S. Department of State Bureau of Consular Affairs Passports and International Travel Statement, November 252014.

M.J. Voors, E.E. Nielsen, P. Verwimp, E.H. Bulte, R. Lensink, and D.P. Van Soest. Violent conflict and behavior: A field experiment in burundi. American Economic Review, 102(2):941-964, 2012.

R. Yehuda. Advances in understanding neuroendocrine alterations in ptsd and their therapeutic implications. Annals of the New York Academy of Sciences, 1071(1):137-166, 2006.

G. Zauberman. The intertemporal dynamics of consumer lock-in. Journal of Consumer Research, 30(3):405-419, 2003. 